\section{Posterior ischaemic optic neuropathy: clinical features, pathogenesis, and management}

SS Hayreh

nonarteritic PION produced significant improvement of visual acuity as well as visual fields, but not so in arteritic or surgical PION. However, some spontaneous visual improvement also occurred in some untreated nonarteritic PION cases.

Conclusions PION is a distinct clinical entity but should be diagnosed only after exclusion of all other causes of visual loss. In all patients older than 50, GCA must be ruled out. There is usually marked visual loss, with central field defect being the most common. The study suggests that high-dose steroid therapy in nonarteritic PION, soon after the onset of visual loss, resulted in significant visual improvement compared to the untreated cases, but not in arteritic and surgical PION.

Eye (2004) 18, 1188-1206.

doi:10.1038/sj.eye. 6701562

Keywords: giant cell arteritis; ischaemic optic neuropathy; posterior ischaemic optic neuropathy; radical neck dissection; spinal surgery

\section{Introduction}

In my studies on the blood supply of the optic nerve, it was found that, unlike the rest of the optic nerve, the anterior part of the optic nerve (optic nerve head) has its own distinct source of blood supply, that is, posterior ciliary arteries (PCAs), which do not supply the rest of the optic nerve. ${ }^{1,2}$ From clinical and experimental studies, I found in 1974 that ischaemic optic neuropathy involving the optic nerve head is a distinct clinical entity, due to interference with the PCA circulation, and I named it anterior ischaemic optic neuropathy (AION). ${ }^{3}$ An accompanying editorial, commenting on my paper, stated: 'The abbreviation AION adopted 
by Hayreh almost of necessity presupposes the existence of a posterior counterpart 'PION' which might, perhaps, be applied to the post-traumatic optic atrophy associated with damage to the optic nerve within its bony canal. ${ }^{4}$ Later, in 1978, having seen more patients with ischaemic optic neuropathy, I classified ischaemic optic neuropathy into two types: AION, involving the anterior part of the optic nerve, and posterior ischaemic optic neuropathy (PION) involving the rest of the optic nerve. ${ }^{5,6}$ In 1981, I submitted a paper describing PION in detail to the Archives of Ophthalmology for publication; it was rejected with the remark that 'there is no reason to believe that any such clinical entity exists'. It was published elsewhere. ${ }^{7}$ Innumerable reports have since established PION as a clinical entity, but all of them except two are anecdotal case reports, based on one or two patients only. The exceptions are: (1) by Isayama et $\mathrm{al}^{8}$ in 14 PION patients and (2) by Sadda et $a l^{9}$ in 72 PION patients.

Thus, based on its blood supply, the optic nerve can be divided into two distinct regions: (a) the optic nerve head almost entirely supplied by the PCA circulation ${ }^{1,2}$ and (b) the rest of the optic nerve (ie posterior part of the optic nerve) supplied from multiple other sources ${ }^{2,10-12}$ (see below). Pathogenetically, as well as clinically, acute ischaemia of the optic nerve results in two very distinct types of ischaemic optic neuropathy: (a) AION involving the optic nerve head, and (b) PION involving a segment of the posterior part of the optic nerve.

Aetiologically, PION can be classified into three types: (1) arteritic PION due to giant cell arteritis (GCA), (2) nonarteritic PION due to causes other than GCA, and (3) surgical PION attributable to a surgical procedure. 9,13

The objective of the present study is to present a comprehensive account of the clinical features, pathogenesis and management of PION based on a retrospective study of 53 consecutive PION eyes of 43 patients, systematically evaluated, treated, and followed during the past 30 years in my Ocular Vascular Clinic at the University of Iowa Hospitals and Clinics.

\section{Materials and methods}

This retrospective study is based on 53 consecutive eyes of 42 Caucasian patients and one Black patient with PION seen in the Ocular Vascular Clinic at the University of Iowa Hospitals and Clinics since 1973, who were systematically evaluated, treated, and followed by me personally, except for three patients, investigated similarly by Dr Randy Kardon, my neuro-ophthalmology colleague.

\section{Inclusion criteria}

I stressed in my original paper on PION: 'There are some diagnoses which should not be made until other possibilities have been carefully ruled out. I think PION is one of these. ${ }^{7}$ I adhered to this rule very strictly in the present study. Therefore, I made all possible attempts to exclude from this study patients whose diagnosis was even slightly in doubt, even if they were referred to me with a diagnosis of PION. My inclusion criteria were: (1) sudden onset of visual deterioration; (2) presence of optic nerve related visual field defect(s); (3) initially, normal optic disc and rest of the fundus on ophthalmoscopy and fluorescein angiography; and (4) exclusion of any other ocular, optic nerve, or neurologic disorders, including compressive, inflammatory, or other mechanisms, as cause of visual loss. For patients with GCA, I used the criterion of positive temporal artery biopsy for GCA, in all but three where for various logistic reasons I could not get a temporal artery biopsy; these three patients had all the classical clinical findings of GCA, including anorexia, weight loss, anaemia, malaise, tender temporal arteries, scalp tenderness, headache, neck pain and jaw claudication, highly elevated erythrocyte sedimentation rate (ESR), and/or C-reactive protein (CRP) and thrombocytosis, so that there was no doubt of their diagnosis of GCA.

PION was nonarteritic in 28 (35 eyes) patients, arteritic in 12 (14 eyes) patients, and surgical in three (four eyes) patients.

At the initial visit, all patients had a detailed systemic and ophthalmic history, including specific questioning, in detail, of patients aged 50 years and older for the ocular and systemic signs and symptoms of GCA. All patients had ophthalmic evaluation by me; this included Snellen visual acuity and visual field testing with a Goldmann perimeter using I2e, I4e, and V4e isopters (unless the visual loss was so severe that the fields could not be plotted), and most of them also had an Amsler grid evaluation of the size of the central scotoma. All had external and slit-lamp examination of the anterior segment, lens and vitreous, intraocular pressure measurement, ophthalmoscopic examination and, almost invariably, fluorescein fundus angiography. All patients aged 50 years and older or suspected to have GCA also had ESR (Westergren) and, from 1985, CRP to rule out GCA; if GCA was suspected, they were promptly started on high-dose steroid therapy, similar to the steroid therapy regimen described in detail elsewhere. ${ }^{14-16}$ Temporal artery biopsy was carried out as soon as convenient to confirm the diagnosis. To rule out other causes of visual loss, including inflammatory, compressive, infiltrative or other forms of optic neuropathy (including Leber's optic neuropathy), 
appropriate investigations were carried out, including orbital echographic, magnetic resonance imaging, and/ or computer tomography, and neurologic evaluation. All nonarteritic patients had a systemic evaluation. At each follow-up visit, all patients had the same evaluation as on the initial visit except for fluorescein fundus angiography.

\section{Steroid therapy}

Arteritic PION To prevent further visual loss, all patients were treated with a steroid therapy regimen similar to that I have used in my other studies in GCA patients; it is described elsewhere. ${ }^{14-16}$

Nonarteritic PION Since there is no known treatment for this and no information was available as to whether steroid therapy is beneficial to these patients or not, all these patients were given the option to try steroid therapy if they wished after a full explanation of the pros and cons of the therapy. Of 28 patients with nonarteritic PION, 14 opted to try the steroid therapy, and it was started the day of the initial visit to the clinic or soon after. The initial dose was usually $80 \mathrm{mg}$ oral Prednisone daily, except for three who were given a single intravenous mega-dose of corticosteroids initially - this was completely random, without any particular reason to do so. Usually, $80 \mathrm{mg}$ Prednisone was given for 2 weeks and then gradually tapered off, with the whole steroid therapy lasting for about $2-2 \frac{1}{2}$ months.

Surgical PION Two of the three had intravenous mega-dose steroid therapy for 2 days on the day the visual loss was discovered, followed by rapid tapering within a few days.

\section{Visual status evaluation}

The visual outcome was evaluated in a masked manner without knowledge of the type of PION, treatment given, or other factors influencing it. The methods used for evaluation of visual acuity and visual fields were exactly the same as described in detail elsewhere. ${ }^{14}$ In addition, visual field loss was originally graded subjectively into arbitrary grades from 0 (normal) to 4 (severe loss) in steps of 0.5 ; the findings were then condensed for descriptive purposes into mild (grades 0.5-1.0), moderate (1.5-2.0), marked (2.5-3.0), and severe (3.5-4.0) loss. The grade was judged by qualitatively assessing on computing clinically the amount of isopteric visual field loss and factoring in the functional disability produced by that defect; for example, inferior and/or central visual field defect, producing far more functional disability, was assigned a much higher grade than a corresponding loss in the upper field or elsewhere. These grades are best described by the following figures: normal in Figure 2c, mild in Figures $2 d$ and $3 c$, moderate in Figures $2 a$ and $3 b$, marked in Figures $1 c, d, 2 b, 3 a$ and $4 a, b$, and severe in Figure 1a,b.

\section{Statistical analyses}

The linear mixed model analysis for repeated measures was used to compare LogMAR visual acuity and visual field grade (0-4-see above) changes in nonarteritic PION eyes that had steroid treatment and those not treated. The factors in the model were treatment (steroid or none), time (baseline and final follow-up), and the treatment-time interaction effect. Specific mean contrasts that were tested included (1) between-treatment group comparison of means at baseline and at last follow-up, and (2) test of mean change from baseline to final followup within each treatment group. The $P$-values for these two sets of comparisons were adjusted using Bonferroni's method. A Bonferroni adjusted $P$-value $<0.05$ was considered statistically significant.

The observed prevalence of seven major systemic diseases in nonarteritic PION patients was each compared with those expected in the age-matched control population from estimates reported for US Caucasian population for 1990-1992 by the National Center for Health Statistics. ${ }^{17}$ Statistical significance was assessed using exact binomial probabilities.

\section{Results}

\section{Demographic characteristics}

This retrospective study had 43 patients (53 eyes): 28 (35 eyes) with nonarteritic PION, 12 (14 eyes) with arteritic PION and three (four eyes) with surgical PION. Nonarteritic PION was seen in 17 women and 11 men (nine right, 12 left, and seven both eyes), arteritic PION in 10 women and two men (three right, seven left, and two both eyes), and surgical PION in 2 women and one man (one right, one left, and one both eyes). Age range was 20-90 (median 61.5, interquartile 52-70) years in nonarteritic PION, 62-83 (median 73.4, interquartile 7179) years in arteritic PION, and 50-82 (median 77.3) years in surgical PION. Of the 12 patients with arteritic PION, three had occult $\mathrm{GCA}^{18}$ with no systemic symptoms or signs of GCA.

\section{Follow-up}

This was evaluated separately for the three types of PION.

Nonarteritic PION Of the 35 eyes, three eyes were followed less than 2 weeks after the onset of PION. 
The follow-up for the remaining 32 eyes after onset varied between 1.3 and 214 (median 16.2) months.

Arteritic PION The follow-up for all the 14 eyes with arteritic PION after onset varied from 1.3 to 55.6 (median 11.4) months.

Surgical PION The four eyes were followed for 4.6, 9.3, 9.3, and 56.6 months after the onset of PION.

\section{Visual symptoms}

Apart from the symptom of sudden visual loss of variable degree, five eyes had also experienced amaurosis fugax before that (three of them with arteritic PION).

\section{Visual acuity}

Table 1 summarizes the initial visual acuity in the three types of PION.

\section{Visual fields}

Table 2 summarizes the various types of visual field defects seen in arteritic and nonarteritic PION on initial examination. Central visual loss, alone or in combination with other types of visual field defects, was the most common visual field defect seen in the present study in PION (Figures 1, 2a,b and 3). For example, in eyes where the visual fields could be plotted, 27 of the 32 eyes $(84 \%)$ with nonarteritic PION and nine of 13 eyes (69\%) with arteritic PION had a central field defect. However, in contrast to this, a marked generalized peripheral constriction, with only a small normal central residual field, was present in one eye with nonarteritic PION and two eyes with arteritic PION (Figure 4). When only a peripheral island visual field was present, in the five nonarteritic PION eyes, it was in the temporal periphery in two, inferior temporal periphery in one and inferior

Table 1 Initial visual acuity in different types of PION

\begin{tabular}{lccc}
\hline Visual acuity & $\begin{array}{c}\text { Nonarteritic } \\
\text { PION }\end{array}$ & $\begin{array}{c}\text { Arteritic } \\
\text { PION }\end{array}$ & $\begin{array}{c}\text { Surgical } \\
\text { PION }\end{array}$ \\
\hline $20 / 20-20 / 25$ & 6 & 4 & 0 \\
$20 / 30-20 / 40$ & 1 & 2 & 0 \\
$20 / 50-20 / 70$ & 3 & 1 & 0 \\
$20 / 80$ & 1 & 0 & 0 \\
20/200-20/400 & 5 & 3 & 0 \\
Counting fingers & 14 & 2 & 1 \\
Hand motion & 2 & 0 & 0 \\
Light perception & 2 & 1 & 0 \\
No light perception & 1 & 1 & 3 \\
& & & \\
Total eyes & 35 & 14 & 4 \\
\hline
\end{tabular}

Table 2 Visual field defects in arteritic and nonarteritic PION eyes

\begin{tabular}{lcc}
\hline Type of visual field defect & $\begin{array}{c}\text { Nonarteritic } \\
\text { PION }\end{array}$ & $\begin{array}{c}\text { Arteritic } \\
\text { PION }\end{array}$ \\
\hline Total eyes & 32 & 13 \\
Superior altitudinal defect & 3 & 0 \\
Inferior altitudinal defect & 0 & 1 \\
Central scotoma alone & 6 & 3 \\
Superior nasal paracentral & 1 & 2 \\
scotoma & 1 & 0 \\
Inferior nasal paracentral & & \\
scotoma & 9 & 2 \\
Central scotoma with other & & 0 \\
field defects & 5 & 2 \\
Centrocecal scotoma alone & 1 & \\
Marked generalized & & 0 \\
constriction only with no & & 0 \\
central scotoma & 1 & 2 \\
Nasal peripheral loss & 2 & \\
Temporal peripheral loss & 5 & 1 \\
Only peripheral island field & & 0 \\
remaining & 4 & 0 \\
$\begin{array}{l}\text { Inferior nasal defect } \\
\text { Superior temporal defect }\end{array}$ & 1 & \\
Superior nasal defect & 2 & \\
Peripheral constriction with & 3 & \\
central defect & &
\end{tabular}

${ }^{a}$ Visual acuity no light perception or too poor to record visual fields in three nonarteritic PION eyes and one arteritic PION eye.

nasal periphery in two; in the two arteritic PION eyes it was located in the inferior periphery in one and inferior temporal periphery in one.

As discussed above, the severity of the visual field loss was graded into mild, moderate, marked, and severe.

Figure 5 gives the information in nonarteritic PION. In arteritic PION, the visual field could not be plotted in one eye with light perception vision only and in the remaining 13 eyes it was mild in five, moderate in one, marked in four, and severe in three. Among the four eyes with surgical PION, in the only seeing eye it was severe.

\section{Optic disc changes}

The optic disc was initially normal in all eyes. The disc developed pallor of variable degree after a variable length of time in all except seven eyes (five with nonarteritic PION and two arteritic PION) with a final visual acuity of $20 / 20$ or $20 / 25$ and no central visual field defect except in two with a tiny paracentral scotoma. This would indicate that these seven nerves suffered little or no permanent ischaemic optic nerve damage. In the eyes that developed optic disc pallor, it was usually not possible to determine the precise time of its onset because logistically it was not possible to examine every patient every week or so. The time interval between these 

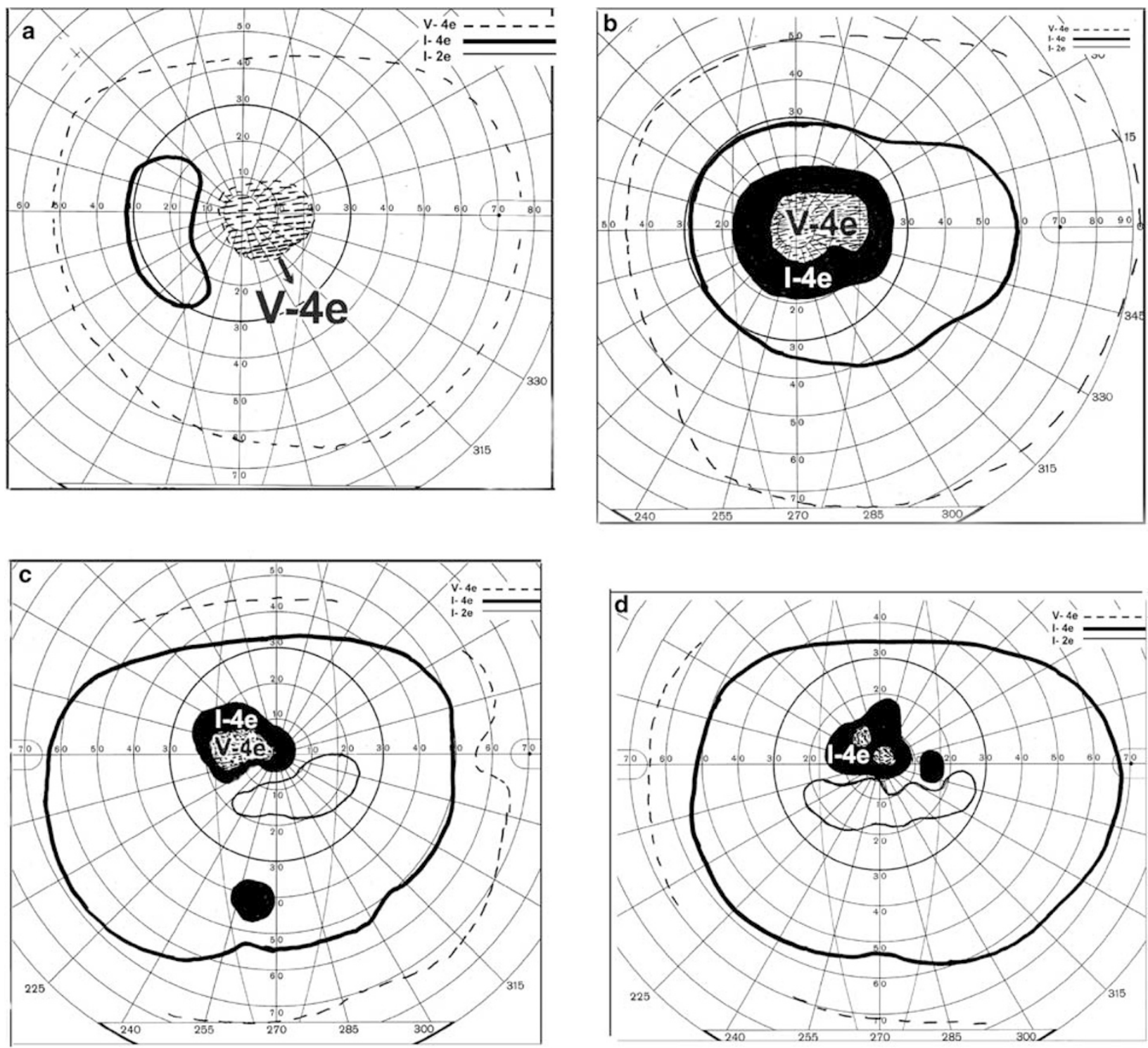

Figure 1 Four visual fields showing varying sizes and densities of central scotoma with normal peripheral visual fields in nonarteritic PION. Right eye fields of (a) a 74-year-old woman and (b) an 87-year-old woman; and (c) and (d) fields in the left and right eyes, respectively, of a 52-year-old man. Note in all figures: scotoma with I4e is the solid black area and with V4e is the dotted area.

patients' visits to the clinic was usually 1 month or even longer for various geographic and climatic reasons. (Our Tertiary Care University of Iowa Hospital draws patients from an area with a radius of about $300-400$ miles.) Also, since the development of pallor is a gradual and subtle process, it is not always possible to pinpoint its exact onset. As far as I could judge, it was usually $6-8$ weeks, although sometimes it was as short as only 3-4 weeks, while in other cases it was over 8 weeks. Whether this depends upon the site of lesion in the optic nerve or severity is hard to comment. In the eyes of the present study, mild-to-moderate temporal pallor of the optic disc was the most common finding, and when a disc had generalized pallor, it was usually more marked in the temporal part - this agrees with central scotoma being the most common visual field defect in PION. There was no evident difference in the optic disc pallor among the different types of PION. In the present series, in two eyes with nonarteritic PION, the disc of the eye with PION developed an increase in cup size compared to the fellow normal eye, in addition to temporal pallor.

\section{Rest of the ophthalmic evaluation}

External and slit-lamp evaluation of the anterior segment, intraocular pressure measurements, and 

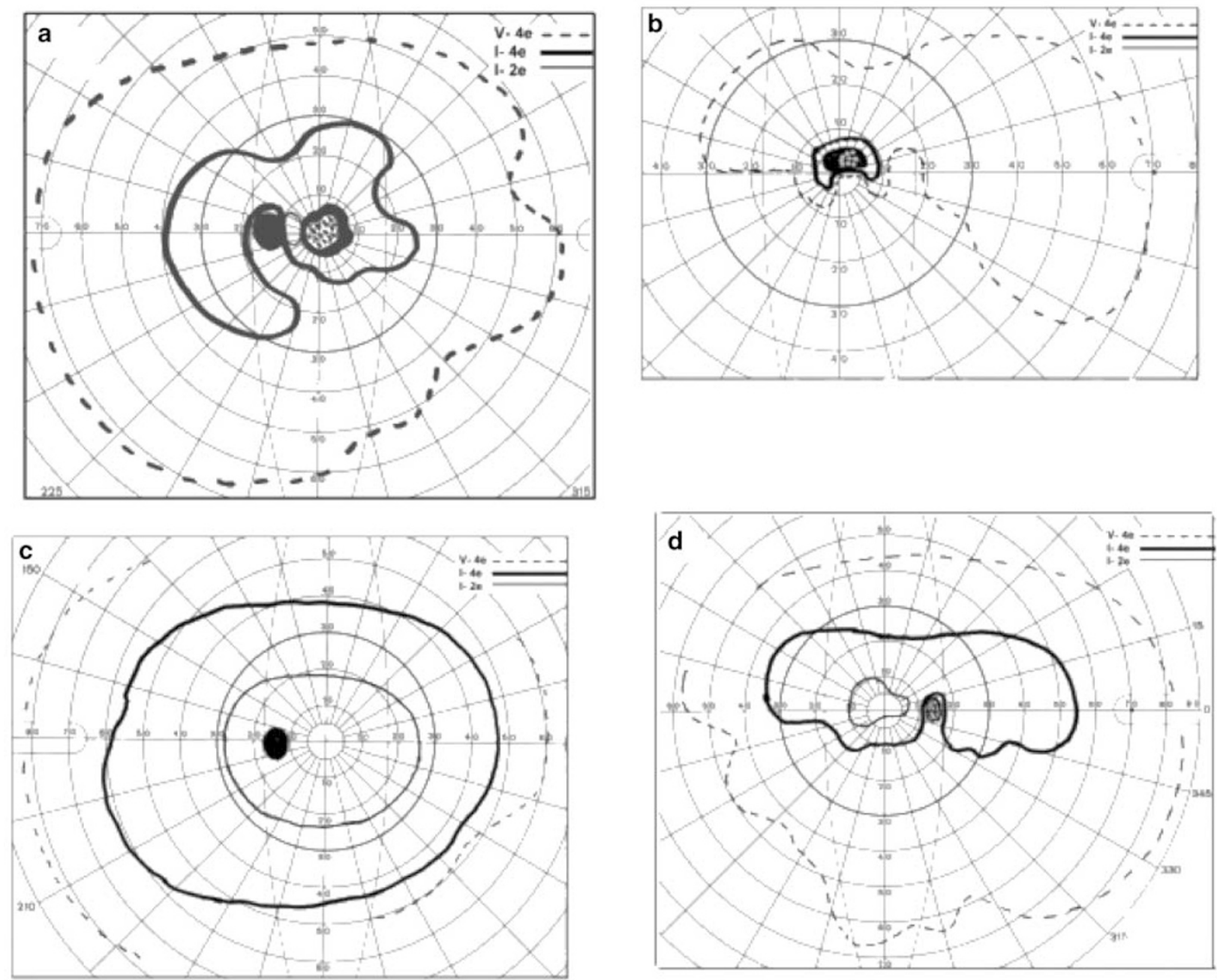

Figure 2 Visual fields of both eyes of a 74-year-old woman with nonarteritic PION, showing marked visual improvement with high-dose steroid therapy. (a) and (b) are visual fields of left and right eyes, respectively, 2 days after the onset of visual loss, with a visual acuity of 20/300 in both eyes. The patient was started on $80 \mathrm{mg}$ Prednisone daily that day. (c) Field of left eye 13 days after (a). (d) Field of right eye 34 days after (b). Total duration of steroid therapy was $2 \frac{1}{2}$ months. Final visual acuity was $20 / 20$ in the left eye and 20/40 in the right eye. After 6 months' follow-up the visual fields and acuity remained stable.

ophthalmoscopy revealed no abnormality in any of these eyes, except for age-related lens changes.

\section{Systemic diseases associated with nonarteritic PION}

The following systemic diseases were seen in 28 patients with nonarteritic PION: arterial hypertension (13 patients), diabetes mellitus (six), ischaemic heart disease (seven), other cardiac diseases (including valvular disease, atrial fibrillation, patent foramen ovale, congestive heart failure, and echocardiographic abnormalities, in six), arterial hypotension (three-orthostatic in one), thyroid disease (three), rheumatologic diseases (three - two of them had systemic lupus), cerebrovascular accidents (five), carotid artery disease (stenosis and/or plaque in nine), peripheral vascular disease (one), vasospastic diseases (migraine in four and Raynaud's disease in one), gastrointestinal ulcer (four), smoking (in nine $-34 \pm 15$ pack years) and hypercholesterolaemia (11). Magnetic resonance imaging and/or computer tomography was performed in 16 patients to rule out any other cause of visual loss. Temporal artery biopsy was performed in eight to rule out GCA.

When the prevalence of major systemic diseases in nonarteritic PION patients of the present study was compared with those expected in the age-matched control population in the US Caucasian population, it showed a significantly higher prevalence of arterial hypertension $(P=0.022)$, ischaemic heart disease 

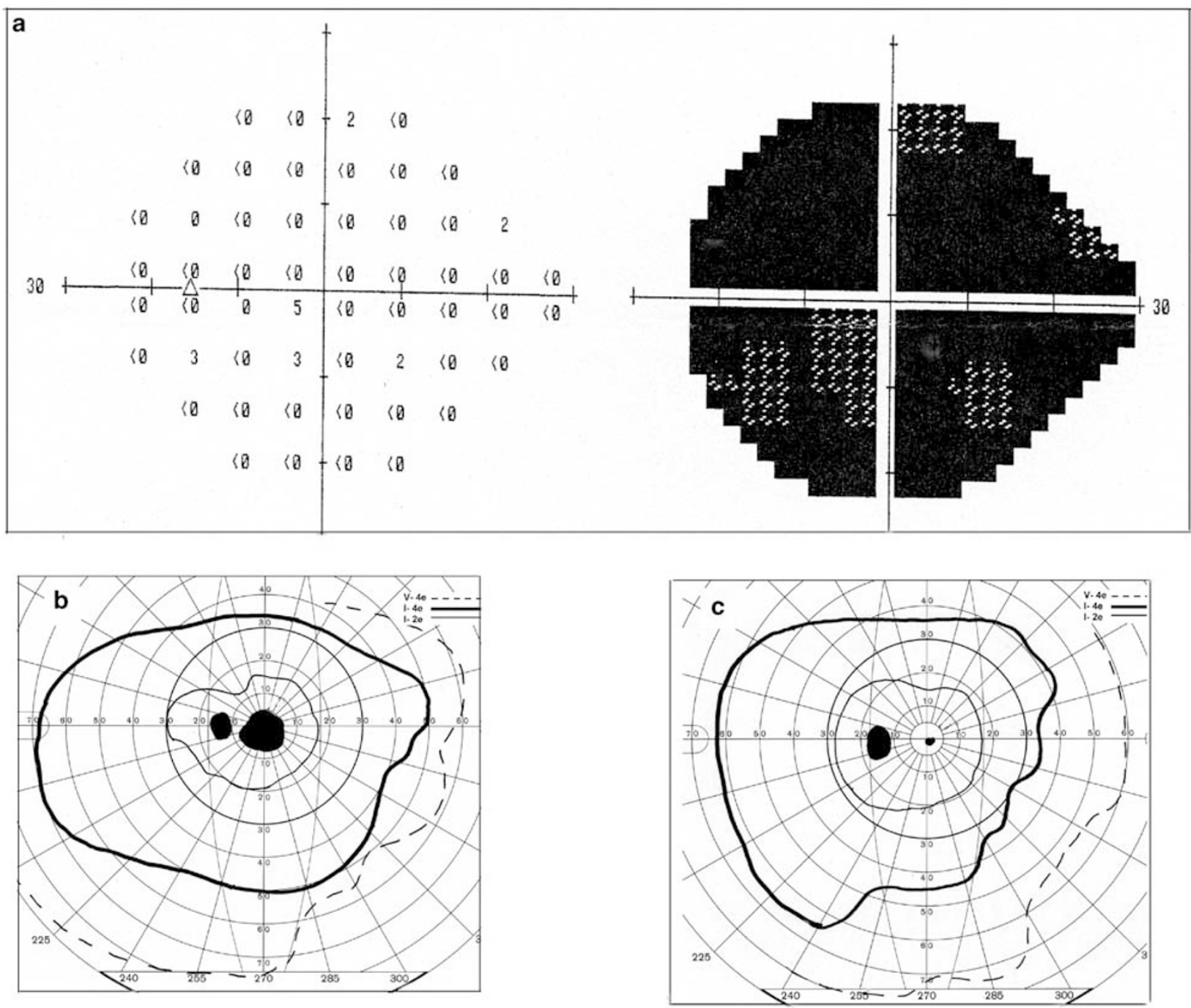

Figure 3 Three visual fields of left eye of an 81-year-old man with nonarteritic PION: (a) on the day of the visual loss, with visual acuity only count fingers. Patient was started on $80 \mathrm{mg}$ Prednisone daily that day. (b) Visual fields the next day with visual acuity 20/30, and (c) 15 days later with visual acuity 20/25. Total duration of steroid therapy was 2 months. On a follow-up of 19 months the visual fields and acuity remained stable.

$(P=0.026)$, cerebrovascular disease $(P=0.006)$, carotid artery and peripheral vascular disease $(P<0.0001)$, diabetes mellitus $(P=0.014)$, migraine $(P=0.039)$, and gastrointestinal ulcers $(P=0.011)$ in the nonarteritic PION patients.

\section{ESR and CRP}

In patients with nonarteritic PION, the median ESR was 25 (range 1-89) $\mathrm{mm} / \mathrm{h}$, and CRP $<0.5 \mathrm{mg} / \mathrm{dl}$ in all patients except $2(1.1 \mathrm{mg}$ in one and $10.6 \mathrm{mg}$ in another with myocardial infarction, and congestive heart failure - in both the temporal artery biopsy was negative). In patients with arteritic PION, the median
ESR was 90.5 (range 13-130) $\mathrm{mm} / \mathrm{h}$, and median CRP 4.75 (range $1.5-12.2$ ) $\mathrm{mg} / \mathrm{dl}$.

\section{Surgical PION}

In the present study, there were only three patients with surgical PION. This is a newly emerging type of PION, with medicolegal implications. Therefore, I feel that a summary of their case reports is instructive.

1. A 55-year-old woman, with arterial hypertension and ischaemic heart disease, had lumbar fusion spinal surgery in the prone position lasting for about $6 \mathrm{~h}$. At the end of the procedure, she had bilateral gross facial and orbital oedema. During surgery she lost about 

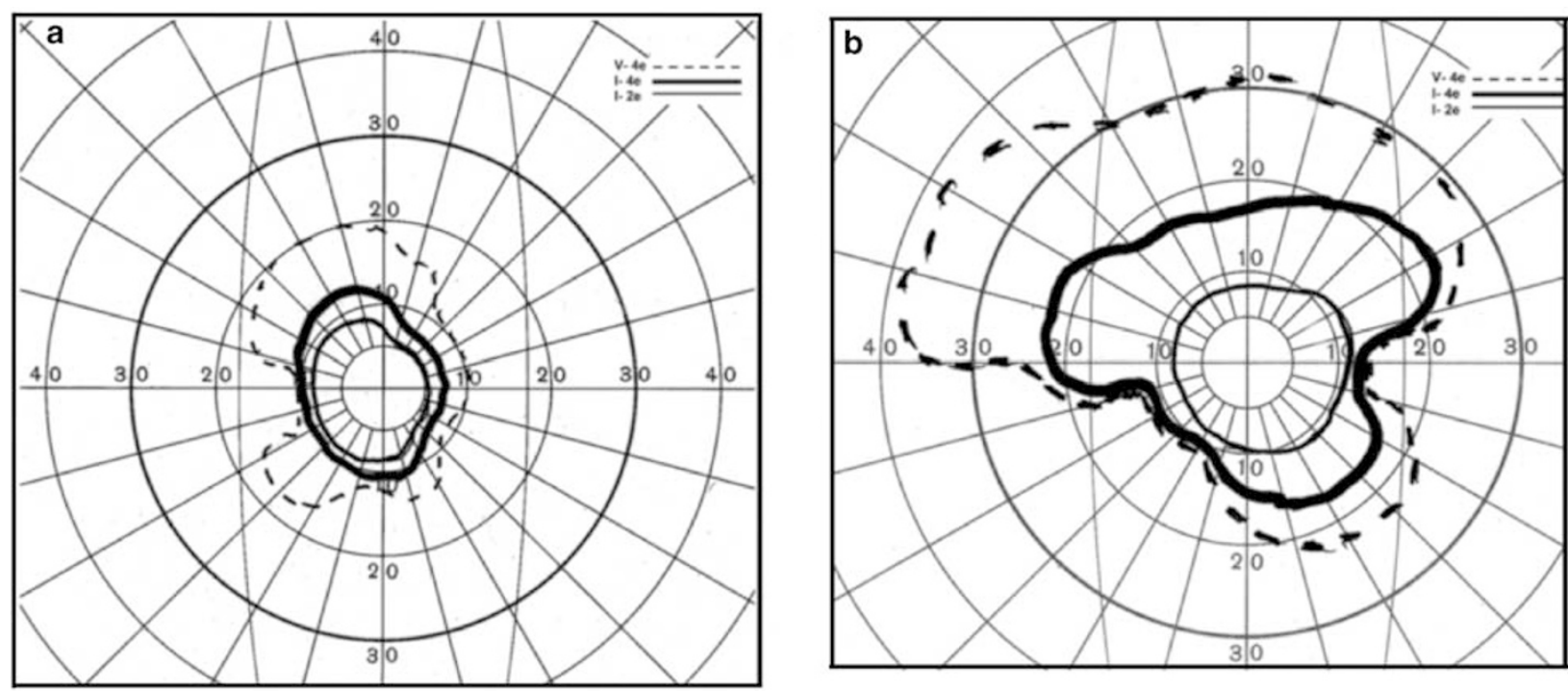

Figure 4 Visual fields of (a) right and (b) left eyes of a 79-year-old woman with arteritic PION, showing remaining, markedly constricted central visual fields, with complete loss of peripheral fields in both eyes.
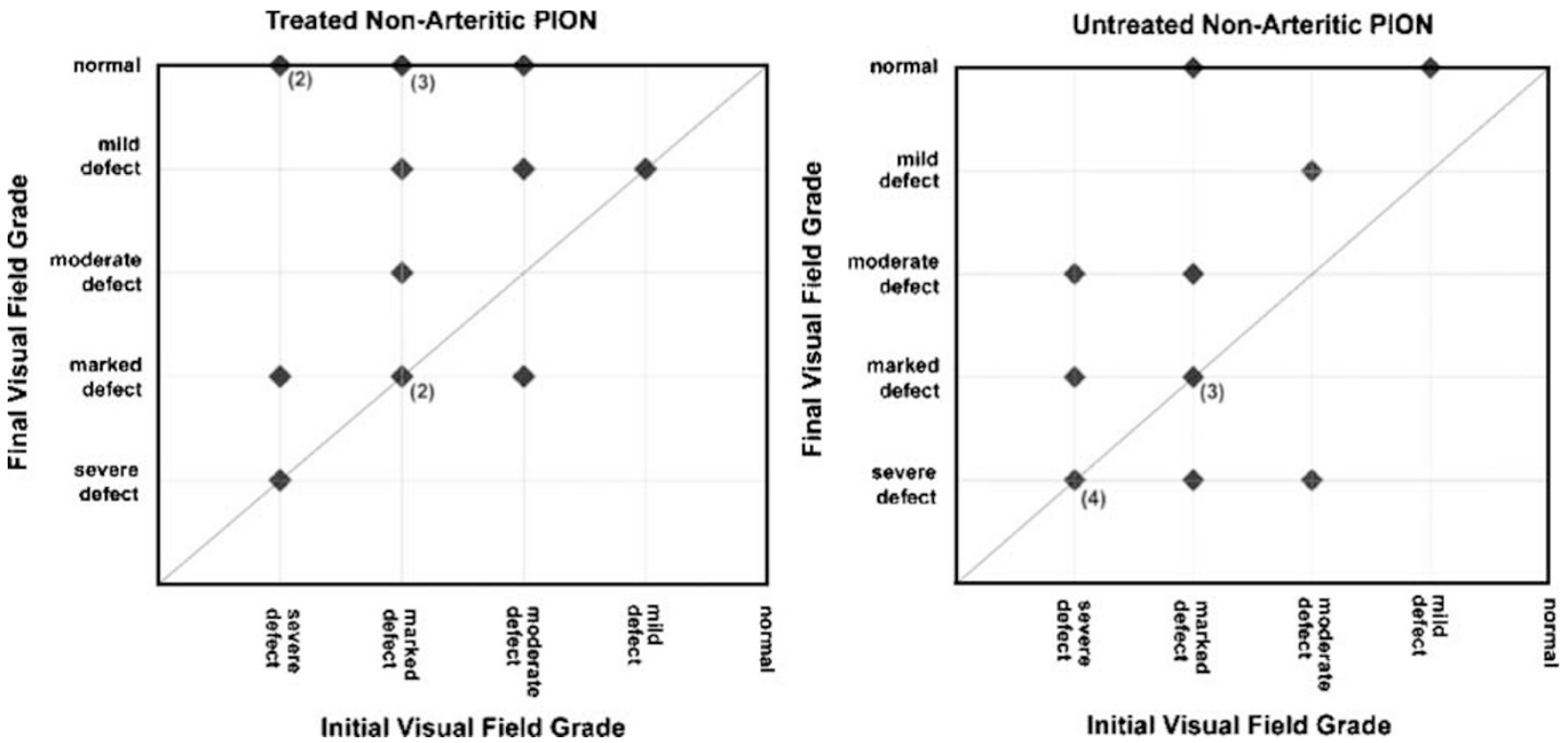

Figure 5 Two graphs showing change from initial to final visual fields in 15 eyes of patients treated with steroid therapy (left graph) and 15 eyes of those not treated (right graph). Normal = normal visual fields.

$400 \mathrm{ml}$ of blood, and her systolic blood pressure was around $90 \mathrm{mmHg}$ and diastolic around $60 \mathrm{mmHg}$, and later, during recovery from anaesthesia, diastolic blood pressure was as low as $45 \mathrm{mmHg}$. When she became alert after surgery, she reported no light perception in both eyes. Both fundi were normal. Magnetic resonance imaging of the brain and orbits showed no abnormality. She had intravenous megadose steroid therapy for 2 days followed by rapid tapering, without any benefit. The eyes did not recover any vision on a follow-up for 9 months and developed bilateral optic atrophy.

2. A 17-year-old man developed orbital floor fracture on the left side following football injury. The left eye had normal visual acuity on examination that day and also the next day after recovery from anaesthesia for surgery to repair the fracture. However, later that day he developed marked orbital oedema. When seen next 
morning he had no light perception in that eye. The optic disc and fundus were normal, and electroretinography was normal. He had intravenous megadose steroid therapy for 2 days followed by rapid tapering, without any benefit. The eye did not recover any vision on a follow-up for 16 months and developed optic atrophy.

3. An 82-year-old woman had cataract surgery in her right eye with retrobulbar anaesthesia. At her first chance to see with that eye the next day, she reported only count fingers vision. The visual field examination showed a large absolute central scotoma with a normal peripheral field. The optic disc and fundus were perfectly normal. At 5 weeks after surgery, the optic disc developed pallor. The visual acuity and fields did not change on follow-up for almost 5 years. In her medical history, she had arterial hypertension, hyperlipidaemia, mitral annular calcification, transient ischaemic attacks, cortical atrophy on magnetic resonance imaging, erythrocyte sedimentation rate $27 \mathrm{~mm} / \mathrm{h}$, and C-reactive protein $0.1 \mathrm{mg} / \mathrm{dl}$.

\section{Effect of steroid therapy on visual function}

The following criteria were used for visual acuity improvement. (a) Visual acuity improvement must be at least $\geqslant 2$ lines of Snellen chart; (b) There must be concomitant improvement in the central $5^{\circ}$ of visual fields, to rule out apparent visual acuity improvement from simple eccentric fixation or learning experience; and (c) The visual improvement must have been maintained on follow-up and not be just fluctuation or transient.

In nonarteritic PION This was evaluated in 32 of the 35 eyes with nonarteritic PION, because the remaining three eyes of two patients had a follow-up of less than 2 weeks and were excluded from this evaluation. Of the 32 eyes, 16 were of patients treated with high-dose steroid therapy (see above for therapy regimen) and the remaining 16 had no treatment. Visual improvement was evaluated on follow-up by the change in visual acuity, as well as central and peripheral visual fields.

\section{Visual acuity}

Figure 6 gives the initial pretreatment and final visual acuity in the treated group, and initial and final visual acuity in the untreated group.

Visual acuity improvement in nonarteritic PION In the treated group of 16 eyes, nine showed improvement by $\geqslant 2$ lines of Snellen chart (Figure 6). Two of the 16 eyes had an initial visual acuity of 20/20-20/25, and therefore could not have shown any significant improvement; they were excluded from data analysis on visual acuity improvement. Of the remaining 14 eyes with an initial visual acuity of 20/40 or worse, nine eyes (64\%) showed visual improvement. Among the 16 eyes of untreated patients, four showed visual acuity improvement (Figure 6). Again, four of the 16 eyes, with an initial visual acuity of 20/20-20/25, were excluded from data analysis for visual acuity improvement. Of the remaining 12 eyes with a visual acuity of $20 / 70$ or worse, four $(33 \%)$ improved.

Of the eyes that had visual acuity at baseline 20/40 or worse, the mean visual acuity (log MAR) at baseline did not differ significantly between the steroid treated and untreated eyes $(P=0.165)$, indicating that the two groups had similar visual acuity to begin with. The treated eyes showed a significant improvement from baseline acuity $(P=0.031)$, with the mean acuity at final follow-up being significantly better than the untreated eyes $(P=0.023)$. Thus, the findings of this study showed that eyes of patients treated with high-dose systemic steroid therapy showed significant visual acuity improvement compared to untreated eyes.

Visual acuity stable or worse in nonarteritic PION

Of the 16 eyes in the treated group, five remained stable (20/20-20/25 in two, 20/80 in one, hand motion in one and no light perception in one), and two deteriorated (from 20/40 to 20/400, and 20/60 to 20/400). Of the 16 eyes in untreated group, nine remained stable (20/ 25-20/25 in four, and count fingers in five), and two deteriorated (from 20/200 to count fingers).

Time interval between the onset of visual loss and start of steroid therapy

This was as follows. (i) In nine eyes with improvement: the therapy was started the same day 5, and 2, 7 and 9 days later in 2, 1, and 1, respectively. (ii) In two eyes with deterioration: it was started 27 days after the onset when the patient was first seen. (iii) In five eyes with stable visual acuity of 20/20,20/25,20/80, hand motion and no light perception, it was started 1, 27, 7, 5, and 24 days, respectively, after onset.

Time interval between start of steroid therapy and onset of visual improvement

It was the day after the start of therapy in four, and after $7,9,13$, and 16 days, with no data in one eye. In the four untreated eyes with visual acuity improvement, it was seen $4,6,43$, and 53 days after the onset of PION. 

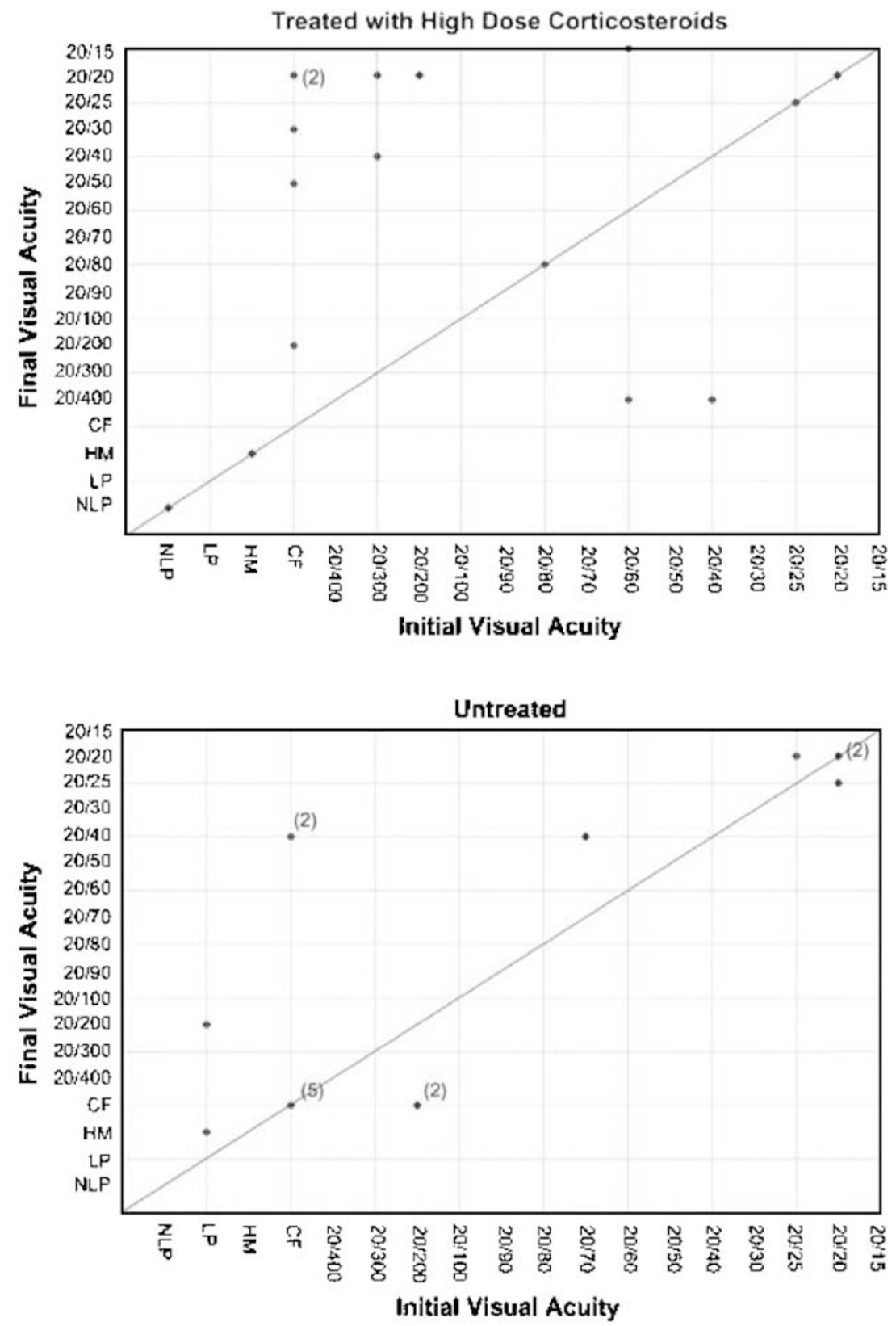

Figure 6 Two graphs showing change from initial to final visual acuity in 16 eyes of patients treated with steroid therapy (upper graph) and 16 eyes of those not treated (lower graph).

\section{Visual fields}

Figure 5 shows the changes in the visual fields in eyes with nonarteritic PION (both treated and untreated groups) during follow-up. The mean visual field grade at baseline did not differ significantly between the steroid treated and untreated eyes $(P=1.000)$, indicating that the two groups were similar to begin with. The eyes of the untreated group did not show a significant improvement from baseline ( $P=0.465)$. In contrast to that, the eyes of the treated group showed a significant improvement from baseline $(P<0.001)$ and it was significantly greater $(P=0.030)$ than in the untreated eyes. The data also indicated a better mean visual field grade at final follow-up for the treated eyes compared to the untreated eyes $(P=0.064)$. Thus, the findings of this study showed that eyes of patients treated with high-dose systemic steroid therapy showed significant visual field improvement compared to untreated eyes. 
Table 3 Visual field change during follow-up in nonarteritic (treated and untreated) and arteritic PION eyes

\begin{tabular}{|c|c|c|c|c|}
\hline Type of PION & $\begin{array}{l}\text { Visual field } \\
\text { change during } \\
\text { follow-up }\end{array}$ & $\begin{array}{l}\text { Central field } \\
\text { only (eyes) }\end{array}$ & $\begin{array}{c}\text { Peripheral field } \\
\text { only (eyes) }\end{array}$ & $\begin{array}{c}\text { Both central } \\
\text { and peripheral field } \\
\text { defects (eyes) }\end{array}$ \\
\hline \multirow{3}{*}{ Steroid treated nonarteritic PION group ${ }^{\text {a }}$ (15 eyes) } & Improved & 4 & 2 & 6 \\
\hline & Stable & 2 & 4 & 1 \\
\hline & Worse & 0 & 0 & 2 \\
\hline \multirow[t]{3}{*}{ Untreated nonarteritic PION group ${ }^{a}$ (15 eyes) } & Improved & 2 & 3 & 3 \\
\hline & Stable & 3 & 2 & 3 \\
\hline & Worse & 0 & 0 & 4 \\
\hline \multirow[t]{3}{*}{ Arteritic PION group ${ }^{\mathrm{b}}$ (13 eyes) } & Improved & 2 & 1 & 1 \\
\hline & Stable & 1 & 2 & 9 \\
\hline & Worse & 0 & 0 & 0 \\
\hline
\end{tabular}

${ }^{\mathrm{a}}$ One eye in both the treated and untreated groups had unreliable fields to evaluated change.

${ }^{\mathrm{b}}$ One eye had unreliable fields to evaluate change.

Arteritic PION Treating these patients with high doses of steroid therapy is mandatory to prevent any further visual loss. None of the 14 eyes showed any significant visual acuity change. Table 3 shows the changes in the central and peripheral visual fields in these eyes during follow-up; however, the mild improvement seen in visual fields in some was not sufficient to improve visual function very much.

Surgical PION There were only four eyes (three patients) in this group. Two patients (three eyes with no light perception) were treated with intravenous steroid therapy immediately on discovery of visual loss, but neither of them recovered any vision. The untreated eye also did not improve.

Recurrence of PION in the same eye This occurred in one patient with bilateral nonarteritic PION who was followed for 14.5 years. The second episode occurred in the right and left eyes 2 and 11 months, respectively, after the first episode. He had systemic lupus erythematosus, and the recurrence coincided with its flare-up.

\section{Discussion}

Aetiologically, PION can be classified into three types: (1) arteritic PION due to GCA, (2) nonarteritic PION due to causes other than GCA, and (3) surgical PION attributable to a surgical procedure., ${ }^{9,13}$ Although PION is seen mostly in the middle-aged and elderly population, no age is immune to it. In the present series, the median age was 61.5 years in nonarteritic PION, 73.4 in arteritic PION, and 77.3 in surgical PION. The median age in AION is very similar, that is, in nonarteritic AION 61 years ${ }^{19}$ and in arteritic AION 76.6 years. ${ }^{20}$ The youngest patient in my series with nonarteritic PION was 20 years old, in the Sadda $e$ a $l^{9}$ series 18 years old, and Gerber et $a l^{21}$ reported this in a 15 -year-old patient.

\section{Clinical features of PION}

Clinically, patients with arteritic and nonarteritic PION typically present with acute, painless visual loss in one or both eyes, sometimes discovering it upon waking up in the morning. In some eyes it may be progressive initially (see above). Patients with surgical PION usually develop visual loss after a prolonged, major surgical procedure; they discover visual loss as soon as they are alert, which may be several days after surgery. Surgical PION usually tends to cause bilateral massive visual loss or even complete blindness that is usually permanent. ${ }^{9}$

On examination, the visual acuity may vary from normal to no light perception (Table 1). In PION there are optic nerve-related visual field defects (Table 2). The present study showed that a central visual field defect is the most common type (Figures 1, 2a,b, and 3) $-84 \%$ in nonarteritic PION and $69 \%$ in arteritic PION. The rest of the ophthalmic evaluation shows no ocular abnormality except for the presence of relative afferent pupillary defect in the involved eye in uniocular PION. Initially there is no fundus or optic disc abnormality on ophthalmoscopy and fluorescein fundus angiography. Unlike nonarteritic AION, the optic disc in nonarteritic PION does not have a high prevalence of absence of cup. Usually, within 6-8 weeks the disc develops pallor that is usually more marked in the temporal part. In the present study, rarely the optic disc developed cupping in nonarteritic PION; this was also reported by Sonty and Schwartz. ${ }^{22}$ In persons 50 years and older it is essential to rule out GCA. The criteria to differentiate arteritic from nonarteritic PION are basically the same as those to differentiate arteritic and nonarteritic AION, ${ }^{16,23}$ except that the optic disc is normal initially in both types in PION, whereas in arteritic AION there is initially a chalky white swelling in $68.7 \%{ }^{20}$ and later on the disc develops cupping and atrophy. 
In the literature, information on the clinical features of PION consists almost entirely of anecdotal reports of one or two patients, except for two retrospective studies: (1) by Isayama et $a l^{8}$ in 14 patients and (2) by Sadda et $a l^{9}$ in 72 patients. As far as I can judge, all cases in the Isayama et $a l^{8}$ series had nonarteritic PION. Among the 72 patients in the Sadda et $a l^{9}$ series, $53 \%$ had nonarteritic, $8 \%$ arteritic, and 39\% surgical PION. In the present study, of the 43 patients, $65 \%$ had nonarteritic, $28 \%$ arteritic, and $7 \%$ surgical PION. The clinical findings in any PION study depend upon not only the number of patients in various types of PION but also on the study design. For example, the present study and that of Sadda et $a l^{9}$ have some fundamental differences, and consequently very different findings. In my study, all the data from all the patients were collected systematically by me in a uniform manner and to a uniform standard. Also, there were only a few surgical PION cases in my series, because I see medicolegal cases very rarely. In the study by Sadda et al, by contrast, the information was obtained by retrospective review of charts of patients seen in the neuro-ophthalmology clinics of two institutions (in Baltimore and Atlanta, USA), with some of the initial data obtained from examination by the referring ophthalmologists (which the authors state were 'often incomplete'), and follow-up information in patients who did not return for follow-up was obtained from review of medical records of 'other physicians' or from 'the closest living relative if the patient was deceased'.

Since the diagnosis of PION, and especially nonarteritic PION, is usually hard to make with certainty, it is difficult to ascertain its true incidence. When I first described this as a disease entity, I stressed that it is a diagnosis of exclusion. ${ }^{7}$ It should be made only after all other possibilities have been carefully ruled out, for example, macular and retinal lesions, nonarteritic AION, retrobulbar optic neuritis, compressive optic neuropathy, other optic disc and optic nerve lesions, neurological lesions, hysteria, even malingering, and a host of other lesions. In my study none of the patients during followup showed any evidence of any of those lesions. The findings of my study, as well as those of others, indicate that a combination of the following findings is highly suggestive of PION: (a) sudden onset of visual deterioration, with or without deterioration of central visual acuity, (b) optic nerve-related visual field defects in the involved eye, (c) the presence of a relative afferent pupillary defect in the involved eye in patients with a perfectly normal fellow eye, (d) initially, normal optic disc and fundus on ophthalmoscopy and fluorescein fundus angiography, (e) no other ocular, orbital, or neurological abnormality to explain the visual loss, and (f) development of optic disc pallor usually within 6-8 weeks. Optic disc in eyes with nonarteritic AION usually has absent cup, which is not the case in PION. The diagnosis of surgical PION, on the other hand, is relatively straightforward; these patients discover dramatic visual loss as soon as they are alert enough after a major surgical procedure, and have the above clinical findings. This, combined with the medicolegal implications, can result in an erroneous impression that surgical PION is more common than other types of PION.

\section{Blood supply of the posterior part of the optic nerve}

For a logical understanding of the various clinical features, histopathological changes, and pathogenesis of PION, it is essential to have an in-depth knowledge of the blood supply of the posterior part of the optic nerve. I have discussed the subject in detail elsewhere., ${ }^{2,10-12}$ Briefly, for purposes of description of blood supply, the posterior part of the optic nerve can be divided into intraorbital, intracanalicular, and intracranial parts.

\section{Intraorbital part}

This is further subdivided by point of entry of the central retinal artery in the optic nerve into (a) anterior and (b) posterior segments (Figure 7).

(a) Anterior segment This is between the optic nerve head and the site of entry of the central retinal artery into the nerve. This part has two vascular systems for its

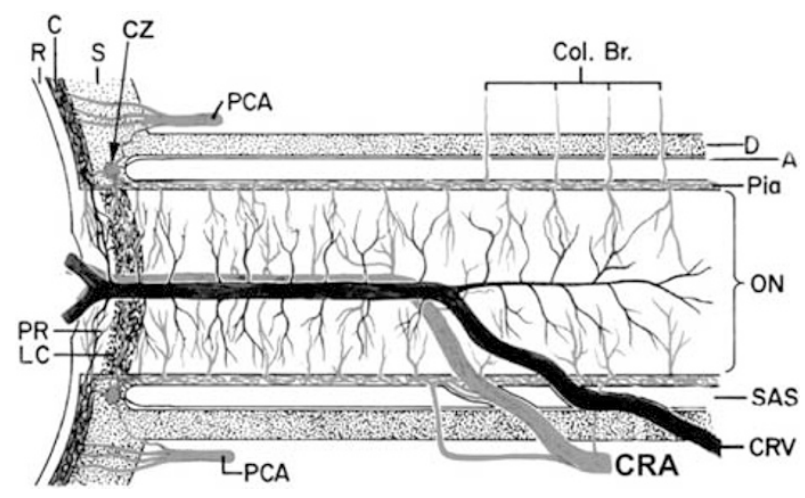

Figure 7 Schematic representation of blood supply of the optic nerve. (Modified from Hayreh, SS Trans Am Acad Ophthalmol Otolaryngol 1974;78:OP240-OP254.) Abbreviations: $\mathrm{A}=$ arachnoid; Ant. Sup. Hyp. Art. = anterior superior hypophyseal artery; $\mathrm{C}=$ choroid; $\mathrm{CRA}=$ central retinal artery; Col. $\mathrm{Br}$. = colcollateral branches supplying the optic nerve pial plexus; $\mathrm{CRV}=$ central retinal vein; $\mathrm{CZ}=$ circle of Zinn and Haller; $\mathrm{D}=$ dura; $\mathrm{ICA}=$ internal carotid artery; $\mathrm{LC}=$ lamina cribrosa; LPCA $=$ lateral posterior ciliary artery; Med. Mus.=medial muscular artery; $\mathrm{MPCA}=$ medial posterior ciliary artery; $\mathrm{OA}=$ ophthalmic artery; $\mathrm{ON}=$ optic nerve; $\mathrm{P}=$ pia; $\mathrm{PCA}=$ posterior ciliary artery; $\mathrm{PR}=$ prelaminar region; $\mathrm{R}=$ retina; $\mathrm{Rec} . \mathrm{Br} . \mathrm{CZ}=$ recurrent pial branches from peripapillary choroid/CZ; $\mathrm{S}=$ sclera; $\mathrm{SAS}=$ subarachnoid space. 
supply. (i) A peripheral centripetal vascular system is present in all cases and is formed by pial vascular plexus, supplied by multiple pial branches originating from the peripapillary choroid, circle of Zinn and Haller, central retinal artery, ophthalmic artery, and other orbital arteries (Figures 7-9). ${ }^{10-12,24,25}$ (ii) An axial centrifugal vascular system is present in $75 \%$ of the nerves and supplied by 1-8 intraneural branches of the central retinal artery (Figures 7 and 9). ${ }^{10,25,26}$

(b) Posterior segment This is primarily supplied by the peripheral centripetal vascular system formed by the pial vascular plexus, supplied by multiple small collateral arteries usually arising directly from the ophthalmic artery and less often from other orbital arteries (Figures 7 and 8$).{ }^{24}$ In about $10 \%$ of the optic nerves, there may be an axial centrifugal vascular system extending backward for a variable distance, formed by intraneural branches of the central retinal artery (Figure 9). ${ }^{10,25,26}$

\section{Intracanalicular part}

This has only the peripheral centripetal system, supplied almost entirely by fine collateral branches from the

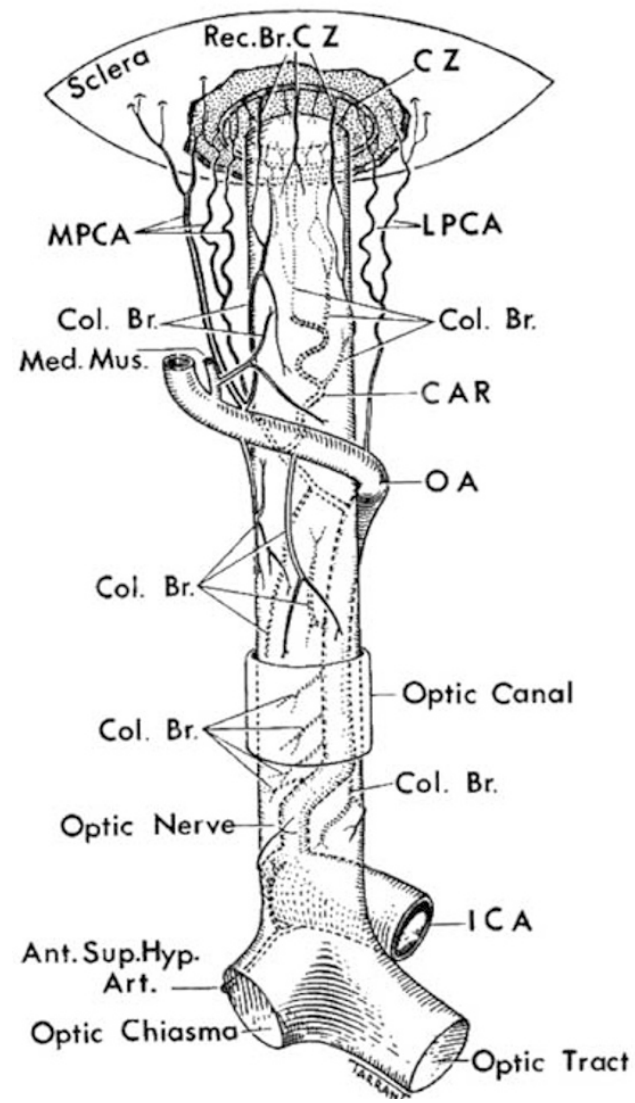

Figure 8 Diagrammatic representation of origin, course, and branches of ophthalmic artery, as seen from above. (Reproduced from Hayreh. ${ }^{25}$ ) See Abbreviations in Figure 7.

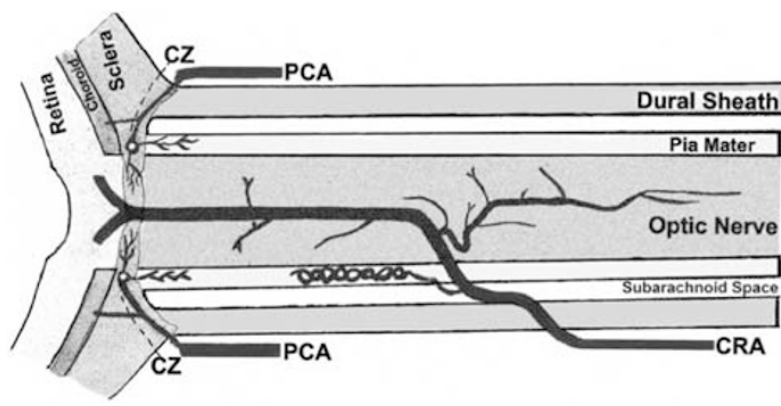

Figure 9 Diagram (based on camera lucida drawings) showing one of the intraneural branches of the central retinal artery running backward in the axial part of the optic nerve posterior to the central retinal artery; from one of the specimens in my anatomical study on the central retinal artery in humans. ${ }^{26}$ See Abbreviations in Figure 7.

ophthalmic artery lying inferior to the optic nerve (Figure 8). ${ }^{12,24 .}$

\section{Intracranial part}

This once again has only a pial vascular plexus, supplied by a variable and inconsistent number of fine branches coming from various surrounding arteries, including anterior superior hypophyseal, anterior cerebral, anterior communicating, and ophthalmic arteries (Figure 8). ${ }^{12,27 .}$

\section{Histopathological findings in PION}

There are several histopathological reports on PION. ${ }^{28-32}$ Each report is based on evaluation of one patient, except that of Isayama and Takahashi, ${ }^{28}$ which is based on 12 cases. They ${ }^{28}$ found that the ischaemic lesions were located in the transverse, peripheral, altitudinal, or axial areas of the optic nerve. Schobel et $a l^{32}$ in their patient with bilateral PION found complete loss of axons in the right nerve whereas the central portion of nerve fibre of the left nerve was intact, with complete loss of axons in the peripheral part. In contrast to this, Weinstein et $a l^{29}$ in their case with PION found that transverse sections through $17 \mathrm{~mm}$ behind the eyeball showed only patchy necrosis, most prominent centrally, with relative sparing of the peripheral part. In the remaining reports, infarction of the entire optic nerve has been reported.

Why is the peripheral part of the optic nerve sometimes spared in PION, and sometimes the central part of the nerve?

Histopathological studies in PION have shown that in some nerves infarction involves the entire thickness of the nerve, in others only the central part, and in still others only the peripheral part. ${ }^{28-32}$ Similarly, clinically 
an eye with PION may be totally blind, or may show mostly central visual field loss (Figures 1, 2a,b, and 3), or there may be a marked generalized constriction of the visual field with preservation of tunnel-like central vision (Figure 4). These variations in the optic nerve involvement in PION depend upon its blood supply pattern, particularly with respect to the role of the central retinal artery in it (see above). If the entire blood supply is by centripetal branches from the pial plexus, then the central part is the most distal part of supply by the terminal capillaries of these branches (Figure 7). The terminal capillary bed is most vulnerable to hypoperfusion and ischaemia - in the German literature this phenomenon has been aptly named wipfeldüre, which literally means withering away of the outermost twigs of a tree because nutrition is not reaching them. This makes the central part of the posterior optic nerve a watershed zone, rendering it more vulnerable to ischaemia than the more peripheral part. Table 2 shows that the most common visual field defect in both arteritic and nonarteritic PION was the central defect. On the other hand, when the posterior part of the optic nerve has a centrifugal vascular system supplied by the central retinal artery (Figure 9) and the circulation in the central retinal artery is not yet compromised because of blood flow autoregulation in it, it may prevent ischaemic damage to the central part of the nerve, although the peripheral part supplied by the fine pial capillary plexus with low pressure is damaged.

As is evident from the above description, the posterior part of the optic nerve is supplied by multiple branches arising from multiple sources (Figure 8). ${ }^{10-12,24,25}$ Therefore, PION, unlike AION, does not represent an ischaemic disorder of any one known artery and does not have any specific location in the posterior part of the optic nerve. Any localized segment or part of the posterior optic nerve may be involved. Thus, pathogenetically and clinically AION and PION are very different disease entities, and it is unfortunate that ophthalmologists and neurologists lump them together as 'ischaemic optic neuropathy'.

\section{Pathogenesis of PION}

\section{Arteritic PION}

This is due to GCA; a number of cases with this type of PION have been reported in the literature. ${ }^{7,20,32,33}$ In the older literature, they were called 'retrobulbar optic neuritis' due to GCA. ${ }^{33}$ Although the most common artery involved in GCA is the PCA, resulting in the development of arteritic AION, GCA can sometimes also involve other orbital arteries. Arteritic PION must be due to the involvement of one or more of the collateral branches supplying the posterior part of the optic nerve (Figure 8). Arteritic PION occurs much less commonly than arteritic AION. For example, in our study of 123 eyes with visual loss due to GCA, arteritic AION was seen in 94 eyes and arteritic PION in only $7 .{ }^{20}$

\section{Nonarteritic PION}

An association between nonarteritic PION and a variety of systemic diseases has been reported in the literature. These diseases include diabetes mellitus, ${ }^{8,28,34,35}$ arterial hypertension, ${ }^{8,28,36}$ arteriosclerosis, ${ }^{8,28}$ atherosclerosis, ${ }^{8,36}$ and marked arterial hypotension. ${ }^{8}$ There are anecdotal case reports of PION associated with migraine, ${ }^{9,37}$ systemic lupus erythematosus, ${ }^{7,38}$ polyarteritis nodosa, ${ }^{39}$ carotid artery stenosis or occlusion, ${ }^{28,36}$ carotid artery dissection, ${ }^{40,41}$ pulseless disease, ${ }^{42}$ rupture of aneurysm of anterior cerebral artery, ${ }^{29}$ extradural haematoma, ${ }^{21}$ head injury, ${ }^{28}$ emboli, ${ }^{28}$ aplastic anaemia, ${ }^{28}$ sickle cell SS disease, ${ }^{43}$ haemodialysis, ${ }^{44}$ and following Aspergillus fumigatus infection. ${ }^{29}$ Sadda et $\mathrm{l}^{9}$ in their series of nonarteritic PION patients found a variety of associated systemic diseases. The various systemic diseases seen in nonarteritic PION patients in the present series are listed above. When their prevalence was compared to the control population, there was a significantly higher prevalence of arterial hypertension $(P=0.022)$, ischaemic heart disease $(P=0.026)$, cerebrovascular disease $(P=0.006)$, carotid artery and peripheral vascular disease $(P<0.0001)$, diabetes mellitus $(P=0.014)$, migraine $(P=0.039)$, and gastrointestinal ulcers $(P=0.011)$ in nonarteritic PION patients. This association does not necessarily mean a cause-and-effect relationship to PION, although they may constitute risk factors for the development of PION, especially nonarteritic PION. However, there are some cases where one can find a causal relationship. For example, four of my patients developed PION following an attack of migraine; some patients with severe nocturnal arterial hypotension woke up with visual loss due to PION; severe arterial hypotension in association with a surgical procedure (see below) or haemodialysis can result in PION, and one of my patients developed PION only on the side with $100 \%$ occlusion of the internal carotid artery.

Thus, the pathogenesis of nonarteritic PION, like nonarteritic AION, ${ }^{19}$ is multifactorial in nature, with a variety of systemic diseases (see above), other vascular risk factors and/or local risk factors predisposing an optic nerve to develop PION; defective autoregulation of the optic nerve may also play a role. Finally, one or the other precipitating risk factor acts as the 'last straw' to produce PION. 


\section{Surgical PION}

This entity has also been called postoperative $\mathrm{e}^{45}$ or perioperative. ${ }^{9}$ I have used the term 'surgical PION'13 because it is more inclusive. Surgical PION usually tends to cause bilateral massive visual loss or even complete blindness, which is usually permanent; therefore, it has great medicolegal importance. A large number (mostly anecdotal) of surgical PION cases have been reported in the literature, almost invariably associated with prolonged systemic surgical procedures, for a variety of conditions, including spinal and other orthopaedic surgical procedures ${ }^{46-51}$ radical neck dissection, ${ }^{30-32,52-57}$ venous graft in extremities, ${ }^{58,59}$ coronary artery bypass, ${ }^{60}$ hip surgery, ${ }^{60}$ nasal surgery, ${ }^{61}$ thoracotomy for haemothorax, ${ }^{55}$ penetrating thoracoabdominal injury, ${ }^{62}$ cataract surgery, ${ }^{63}$ and strabismus surgery. ${ }^{64}$ Sadda $e t$ a $l^{9}$ reported 28 patients following a variety of procedures. Although in my series there were only three cases with surgical PION, I have been approached for a medicolegal opinion on several other cases associated with spinal surgery.

The pathogenesis of surgical PION is multifactorial in nature. The main factors include severe and prolonged arterial hypotension (due to prolonged general anaesthesia, surgical trauma, and massive blood loss), haemodilution from administration of a large amount of intravenous fluids to compensate for the blood loss, orbital and periorbital oedema, chemosis and anaemia, and rarely even direct orbital compression by prone position. Cheng et $a l^{65}$ in their study found that prone position during anaesthesia increases IOP, which is most likely a reflection of the increased orbital venous pressure. During spinal surgery the Trendelenburg position is often used, which can further contribute to increased orbital venous pressure and oedema. An increase in orbital venous pressure may also be the result of radical neck dissection. One of the patients with surgical PION in the present series developed it following marked orbital oedema after surgical repair of an orbital floor fracture. Systemic cardiovascular disease and autoregulatory dysfunction would make these patients more susceptible to surgical PION. Some orthopaedic surgeons deliberately produce arterial hypotension during surgery to reduce bleeding. PION develops in these patients due to decreased blood flow in the posterior part of the optic nerve, which may be caused by a combination of the following factors:

(a) Marked and prolonged arterial hypotension is seen almost invariably in these patients during surgery.

(b) Increased venous pressure and tissue pressure in orbital tissues and the orbital optic nerve caused by the following sequence of events: marked orbital oedema $\rightarrow$ increased intraorbital pressure $\rightarrow$ increased orbital venous pressure. Also the Trendelenburg position may contribute to this. In radical neck dissection, ligation of the jugular veins can result in raised orbital venous pressure.

(c) In some cases raised orbital pressure may directly compress the capillary pial plexus of the optic nerve.

Normally, perfusion pressure in a tissue depends upon the difference between the arterial and venous pressures. In these surgical PION patients, increased orbital venous pressure by the above mechanism(s) along with simultaneous arterial hypotension is a dangerous combination, resulting in reduced blood flow to the optic nerve and ischaemia. Some anaesthesiologists give vasopressor agents to increase blood pressure in patients with arterial hypotension during surgery; this also can be dangerous, because these agents increase blood pressure by constricting the terminal arterioles. Constriction of the terminal arterioles has a paradoxical effect- proximal to the arterioles there is increased blood pressure (which gives a false sense of security) but distal to the terminal arterioles (due to constriction of the arterioles) there is marked reduction of blood flow in the capillary bed, resulting in ischaemic damage. Moreover, these agents can also cause vasoconstriction in the optic nerve, making it more susceptible to ischaemic damage.

Several authors have equated visual loss due to surgical PION to that seen in patients with posthaemorrhagic amaurosis, that is, visual loss after recurrent systemic haemorrhages. ${ }^{66}$ The two are actually very different in nature because, in posthaemorrhagic amaurosis visual loss develops: (a) hours, days, or even weeks after systemic bleeding, (b) very rarely after a single haemorrhage, (c) when haemoglobin and blood pressure may be within normal limits, and (d) usually during sleep, or worsens during sleep. ${ }^{66}$ To explain posthaemorrhagic amaurosis, I postulated that the release of angiotensin and other endogenous vasoconstrictor agents (secondary to recurrent massive systemic haemorrhage, with or without arterial hypotension) is most probably a very important factor, with arterial hypotension being an additional important risk factor, and possibly increased platelet aggregation. ${ }^{66}$ Although posthaemorrhagic amaurosis and surgical PION are not identical clinically, they may share these factors in their pathogenesis.

\section{Pathogenesis of various types of visual field defects seen in PION}

To understand this, it is essential to have a full understanding of the arrangement of the optic nerve fibres in the posterior part of the optic nerve and its vascular pattern. The optic nerve fibres rearrange 
themselves as they travel posteriorly in the optic nerve; for example, the macular fibres lie in the temporal part of the optic nerve head but lie in the central part of the optic nerve posteriorly. ${ }^{67}$ Hoyt and Luis ${ }^{68}$ in the Java monkey, however, found that the macular fibres mix freely with those from the peripheral retina and in no portion of the optic nerve except the distal optic nerve are they confined exclusively to a single area or 'bundle'. The implication of this is that segmental ischaemia of the optic nerve head is likely to produce a visual field defect very different from that produced by segmental ischaemia in the posterior part of the optic nerve.

As discussed above, the axial region in the posterior part of the optic nerve is usually a watershed zone, which makes it more susceptible to ischaemic damage than the peripheral part. This may explain the common occurrence of a central visual field defect in PION (Table 2, Figures 1, 2a,b, and 3). In about $10 \%$ of the nerves, by contrast, the axial region of the posterior part of the optic nerve is supplied by an intraneural branch of the central retinal artery (Figure 9), and this helps to protect the axial region from ischaemic damage. That may explain the preservation of a tunnel-like central field in PION in spite of loss of peripheral visual field (Figure 4).

Since each collateral branch supplies a localized area of variable size in the posterior optic nerve (Figures 7 and 8 ), occlusion of different collaterals can result in a variety of visual field defects depending upon their area of supply and the origin of the optic nerve fibres from the retina in that region. Isayama and Takahashi ${ }^{28}$ in their histopathological study in PION found that the ischaemic lesions could be located in the transverse, peripheral, altitudinal, or axial areas of the nerve. That would explain different types of visual field defects seen in PION.

\section{Visual field defects in PION as compared with AION}

To determine whether the pattern of visual field defects in the two types of ischaemic optic neuropathy can help us to differentiate them, I compared the fields plotted with a Goldmann perimeter in the two types of neuropathy in my clinic. In 1978, I analysed the data of the pattern of central and peripheral visual field defects in 133 consecutive eyes with nonarteritic AION seen in my clinic. ${ }^{69}$ In that study, the central visual fields showed no scotoma in $40 \%$, and the main field defects included inferior nasal in $29 \%$ and inferior altitudinal in $29 \%$, much less frequently other types of field defects. In my experience of now dealing with more than 1200 patients with nonarteritic AION, I have found the inferior nasal visual field defect to be by far the most common and characteristic defect in AION, although smaller isopters may reveal an inferior altitudinal defect. Gerling et $a l^{70}$ in a study of visual fields with Goldmann perimeter in 36 patients with AION found inferior altitudinal defect in $52 \%$ (among them $27 \%$ actually had an inferior nasal defect), central scotoma in $18 \%$, and other types of defects much less commonly. These patterns in nonarteritic AION are very different from those in nonarteritic PION seen in the present study (Table 2). The same was true when visual fields in 35 eyes with arteritic AION in my study ${ }^{69}$ were compared with those with arteritic PION in the present study. While evaluating the visual field defects in AION and PION and comparing their prevalence in different published studies, it is important to bear in mind that we cannot compare the visual field defects plotted with the automated $30^{\circ}$ perimetry now commonly used with those plotted with a Goldmann perimeter. This is because, among other problems, a large inferior scotoma extending beyond the central $30^{\circ}$ may erroneously be diagnosed on automated perimetry as an inferior altitudinal defect. I have seen this happen time and again. This differentiation is important because eyes with the so-called 'inferior altitudinal defect' in automated perimetry may have perfectly normal peripheral fields beyond the central $30^{\circ}$. That has functional importance, because that field is helpful for the patients' day to day navigation. Thus, in conclusion, inferior nasal or inferior altitudinal field defects are typical of AION but are rare in PION. Central visual field loss, by contrast, is the most common type of defect in PION.

\section{Why is PION much less common than AION?}

Since 1973, I have seen more than 1200 patients with nonarteritic AION and more than 100 with arteritic AION in my Ocular Vascular Clinic. We know that AION is due to ischaemia of the optic nerve head. During the same period, on the other hand, I have seen only about 28 patients with definite nonarteritic PION and 12 with arteritic PION. This may be due to the very different nature of the blood supply of the optic nerve head compared to that of the posterior part of the optic nerve (Figure 7). The optic nerve head is supplied by the PCA circulation, which is an end-arterial system without any anastomoses with surrounding arteries. ${ }^{71,72}$ The posterior part of the optic nerve is supplied by the pial vascular plexus, which is not an end-arterial system because of the various collateral branches (Figures 7 and 8) supplying it anastomose freely with one another in the pial plexus. ${ }^{10,12,26}$ The anastomoses in the pial plexus may have a protective influence if one or the other collateral branch alone is involved, which is not the case in the endarterial PCA distribution in the optic nerve head. Moreover, the blood flow in the optic nerve head 
depends upon the intraocular pressure (ie perfusion pressure $=$ mean arterial pressure minus the intraocular pressure), which is much higher than the orbital pressure. Thus, a combination of various factors may make the optic nerve head more vulnerable to ischaemic disorders than the rest of the optic nerve.

\section{Management of PION}

The management of PION depends upon the type of PION. In all cases other than surgical PION, the most important first step in persons aged 50 years or older is always to rule out GCA, as in AION. ${ }^{20,23}$

\section{Arteritic PION}

In this, basically it is the management of GCA by prompt, aggressive systemic steroid therapy to prevent further visual loss. In the present study, these patients showed no significant visual improvement with steroid therapy. The steroid therapy regimen used by me in these patients is exactly similar to that for arteritic AION, which I have discussed in detail elsewhere. ${ }^{14-16}$

\section{Nonarteritic PION}

In the present study, the statistical data analysis showed that the eyes of patients treated with high-dose systemic steroid therapy showed significant visual acuity and visual field improvement, compared to untreated eyes (see above). Also, the magnitude of visual acuity and visual field improvement was much greater in the treated group than in the untreated group. Thus, the findings of this study indicate a beneficial effect on visual function of aggressive systemic steroid therapy during the very early stages of the disease (Figures 2 and 3). However, spontaneous improvement in visual acuity and visual field may also occur to some extent in some eyes without steroid therapy. Sadda et $a l^{9}$ reported that visual acuity improved in $34 \%$, remained stable in $28 \%$, and worsened in $38 \%$. However, they did not mention whether any of their patients were treated or not. The authors rightly caution against drawing any definite conclusion from their data about this visual acuity change, because the visual acuity data in their series had several potential drawbacks, including these: (a) visual acuity testing was not standardized, (b) it was not with best refraction, (c) in some cases initial and follow-up visual acuity measurements were obtained from different offices, (d) the times to initial and final visual acuity testing 'varied considerably', and (e) 'no follow-up visual acuity data were ascertainable for $22 \%$ of patients.' Another confounding factor often forgotten when reporting visual acuity improvement is that unless there is a corresponding improvement in the central $5^{\circ}$ of the visual fields, improvement in visual acuity alone may simply represent the patient's learning to fixate eccentrically. ${ }^{14}$ Lastly, in the management of these patients, since systemic risk factors may play a part in the development of nonarteritic PION, one should try to reduce as many risk factors as possible to reduce the risk of second eye involvement.

\section{Surgical PION}

Basically, the management amounts to prophylactic measures to prevent its development because once the visual loss occurs, it is usually bilateral, severe, and irreversible. No treatment has been found to be effective to recover or improve the lost vision. Prophylactic measures during surgery include avoiding arterial hypotension, excessive fluid replacement and haemodilution, pressure on the eyeball and orbit, and dependent position of the head, as well as shortening the duration of surgery to the minimum. Since systemic cardiovascular risk factors may predispose a patient to a higher risk of developing surgical PION, it may be advisable to consider those factors in the decision to perform surgery.

\section{Visual prognosis in PION}

The present study showed that prognosis varies with the type of PION. Eyes with nonarteritic PION in patients treated with high-dose steroid therapy at onset showed significantly greater visual improvement than untreated patients. Patients with arteritic PION, if treated urgently and aggressively with high-dose steroid therapy showed no change in vision but it prevented further visual loss. Patients with surgical PION usually suffer severe, irreversible visual loss and do not respond to steroid therapy. Visual loss often tends to be bilateral; this has also been reported by others. ${ }^{9}$

\section{Strengths and limitations of the present study}

My study has both strengths and limitations. Its strengths are as follows: (i) it is based on the largest series of consecutive patients evaluated, managed, and followed systematically for PION by a single investigator over a 30-year period, eliminating a major source of variability; (ii) all patients had a uniform detailed ocular and systemic evaluation; and (iii) they were fully investigated to exclude any other cause of visual loss. The limitations of the study are that it is (a) strictly speaking a retrospective study, and (b) the steroid therapy in nonarteritic PION was not a randomized one but by patient choice. 


\section{Addendum}

Since the submission of this manuscript, I have seen one more patient with PION. A 46-year-old woman who woke up one morning with marked loss of her central vision in the right eye. When I saw her 6 days later, her visual acuity on slow eccentric fixation was 20/80 and she had an absolute centrocecal scotoma with normal peripheral field in that eye, with the left eye normal. The right fundus showed no abnormality on ophthalmoscopy and fluorescein angiography. All evaluations, including magnetic resonance imaging, revealed no other abnormality. She was started on $80 \mathrm{mg}$ Prednisone daily on the day I first saw her. When seen for follow-up 2 weeks later, the visual acuity in the right eye was $20 / 20$ and the visual field was perfectly normal. Prednisone was then gradually tapered off.

\section{Acknowledgements}

I am grateful to Dr Randy Kardon and Dr Michael Wall, my neuro-ophthalmology colleagues, for their critical review of the manuscript and valuable suggestions, to Dr Randy Kardon for allowing me to include three of his cases, to Dr Bridget Zimmerman for the expert statistical help, to Ms Georgiane Perret for help with bibliography, to Ms Trish Duffel with graphs, and to my wife for her help in the preparation of this manuscript.

\section{References}

1 Hayreh SS. Blood supply of the optic nerve head and its role in optic atrophy, glaucoma and oedema of the optic disc. $\mathrm{Br}$ J Ophthalmol 1969; 53: 721-748.

2 Hayreh SS. Pathogenesis of visual field defects. Role of the ciliary circulation. Br J Ophthalmol 1970; 54: 289-311.

3 Hayreh SS. Anterior ischaemic optic neuropathy I. Terminology and pathogenesis. Br J Ophthalmol 1974; 58: 955-963.

4 Editorial: Ischaemic optic neuropathy. Br J Ophthalmol 1974; 58: 953-954.

5 Hayreh SS. Ischemic optic neuropathy. Int Ophthalmol 1978; 1: 9-18.

6 Hayreh SS. Ischemic optic neuropathy. Acta XXIII Conc Ophthalmol, Kyoto 1978; 1: 313-318.

7 Hayreh SS. Posterior ischemic optic neuropathy. Ophthalmologica 1981; 182: 29-41.

8 Isayama $\mathrm{Y}$, Takahashi T, Inoue M, Jimura T. Posterior ischemic optic neuropathy. III. Clinical diagnosis. Ophthalmologica 1983; 187: 141-147.

9 Sadda SR, Nee M, Miller NR, Biousse V, Newman NJ, Kouzis A. Clinical spectrum of posterior ischemic optic neuropathy. Am J Ophthalmol 2001; 132: 743-750.

10 Singh S, (Hayreh SS), Dass R. The central artery of the retina II. Distribution and anastomoses. Br J Ophthalmol 1960; 44: 280-299.
11 Hayreh SS. The blood supply of the optic nerve and its clinical significance. Acta XIX Conc Ophthalmol New Delhi 1962; 2: 1194-1199.

12 Hayreh SS. Blood supply and vascular disorders of the optic nerve. An Inst Barraquer 1963; 4: 7-109.

13 Hayreh SS. Neuropatías Ópticas Isquémicas. In: Arruga J, Sánchez B (eds). Neuropatías Ópticas: Diagnóstico Y Tratamiento. LXXVIII Ponencia Oficial Soc Espan Oftalmol, 2002, pp 207-237.

14 Hayreh SS, Zimmerman B, Kardon RH. Visual improvement with corticosteroid therapy in giant cell arteritis: report of a large study and review of literature. Acta Ophthalmol Scand 2002; 80: 355-367.

15 Hayreh SS, Zimmerman B. Visual deterioration in giant cell arteritis patients while on high doses of corticosteroid therapy. Ophthalmology 2003; 110: 1204-1215.

16 Hayreh SS, Zimmerman B. Management of giant cell arteritis: our 27-year clinical study; new light on old controversies. Ophthalmologica 2003; 217: 239-259.

17 Vital and Health Statistics. Prevalence of Selected Chronic Conditions: United States, 1990-92, Series 10, No. 194, National Center for Health Statistics, 1997.

18 Hayreh SS, Podhajsky PA, Zimmerman B. Occult giant cell arteritis: ocular manifestations. Am J Ophthalmol 1998; 125: 521-526,893.

19 Hayreh SS, Joos KM, Podhajsky PA, Long CR Systemic diseases associated with non-arteritic anterior ischemic optic neuropathy. Am J Ophthalmol 1994; 118: 766-780.

20 Hayreh SS, Podhajsky PA, Zimmerman B. Ocular manifestations of giant cell arteritis. Am J Ophthalmol 1998; 125: 509-520.

21 Gerber CJ, Neil-Dwyer G, Kennedy P. Posterior ischaemic optic neuropathy after a spontaneous extradural haematoma. J Neurol Neurosurg Psychiatry 1992; 55: 630.

22 Sonty S, Schwartz B. Development of cupping and pallor in posterior ischemic optic neuropathy. International Ophthalmology 1983; 6: 213-220.

23 Hayreh SS. Anterior ischaemic optic neuropathy: differentiation of arteritic from non-arteritic type and its management. Eye 1990; 4: 25-41.

24 Hayreh SS. The ophthalmic artery III. Branches. $\mathrm{Br} \mathrm{J}$ Ophthalmol 1962; 46: 212-247.

25 Hayreh SS. The central artery of the retina- its role in the blood supply of the optic nerve. Br J Ophthalmol 1963; 47: 651-663.

26 Hayreh SS A study of the central artery of the retina in human beings. Thesis for the Master of Surgery, Panjab University, India, 1958.

27 Steele EJ, Blunt MJ. The blood supply of the optic nerve and chiasm in man. J Anat 1956; 90: 486-493.

28 Isayama Y, Takahashi T. Posterior ischemic optic neuropathy. II. Histopathology of the idiopathic form. Ophthalmologica 1983; 187: 8-18.

29 Weinstein JM, Morris GL, ZuRhein GM, Gentry LR. Posterior ischemic optic neuropathy due to Aspergillus fumigatus. J Clin Neuroophthalmol 1989; 9: 7-13.

30 Marks SC, Jaques DA, Hirata RM, Saunders Jr JR. Blindness following bilateral radical neck dissection. Head Neck 1990; 12: 342-345.

31 Nawa Y, Jaques JD, Miller NR, Palermo RA, Green WR. Bilateral posterior optic neuropathy after bilateral radical neck dissection and hypotension. Graefes Arch Clin Exp Ophthalmol 1992; 230: 301-308. 
32 Schobel GA, Schmidbauer M, Millesi W, Undt G. Posterior ischemic optic neuropathy following bilateral radical neck dissection. Int J Oral Maxillofac Surg 1995; 24: 283-287.

33 Hollenhorst RW. Effect of posture on retinal ischemia from temporal arteritis. Arch Ophthalmol 1967; 78: 569-577.

34 Pedrotti MM, Basso AL. Diabetic retrobulbar optic neuropathy. Metab Pediatr Syst Ophthalmol 1986; 9: 94-97.

35 Bertram B, Reim H, Reim M. Beidseitige posteriore ischämische Optikusneuropathie bei einer Jugendlichen mit Diabetes mellitus mit dekompensierter

Blutzuckereinstellung. Klin Monatsbl Augenheilkd 1995; 206: 39-45.

36 Inoue M, Tsukahara Y. Vascular optic neuropathy in diabetes mellitus. Jpn J Ophthalmol 1997; 41: 328-331.

37 Lee AG, Brazis PW, Miller NR. Posterior ischemic optic neuropathy associated with migraine. Headache 1996; 36: 506-510.

38 Jabs DA, Miller NR, Newman SA, Johnson MA, Stevens MB. Optic neuropathy in systemic lupus erythematosus. Arch Ophthalmol 1986; 104: 564-568.

39 Saraux H, Le Hoang P, Laroche L. Neuropathie optique ischeemique aigue anterieure et posterieure au cours d'une peri-arterite noueuse. Traitement par plasmapherese. J Fr Ophthalmol 1982; 5: 55-61.

40 Rivkin MJ, Hedges TR, Logigian EL. Carotid dissection presenting as posterior ischemic optic neuropathy. Neurology 1990; 40: 1469.

41 Tsai R-K, Sun C-Y. Spontaneous dissection of internal carotid artery presenting as isolated posterior ischaemic optic neuropathy. Br J Ophthalmol 1997; 81: 513-517.

42 Kiyosawa M, Asano T. A case of posterior ischemic optic neuropathy associated with pulseless disease. Acta Soc Ophthalmol Jpn 1982; 86: 2050-2055.

43 Perlman JI, Forman S, Gonzalez ER. Retrobulbar ischemic optic neuropathy associated with sickle cell disease. J Neuroophthalmol 1994; 14: 45-48.

44 Buono LM, Foroozan R, Savino PJ, Danesh-Meyer HV, Stanescu D. Posterior ischemic optic neuropathy after hemodialysis. Ophthalmology 2003; 110: 1216-1218.

45 Roth S, Barach P. Postoperative visual loss: still no answers-yet. Anesthesiology 2001; 95: 575-577.

46 Katz DM, Trobe JD, Cornblath WT, Kline LB. Ischemic optic neuropathy after lumbar spine surgery. Arch Ophthalmol 1994; 112: 925-931.

47 Myers MA, Hamilton SR, Bogosian AJ, Smith CH, Wagner TA. Visual loss as a complication of spine surgery. A review of 37 cases. Spine 1997; 22: 1325-1329.

48 Stevens WR, Glazer PA, Kelley SD, Lietman TM, Bradford DS. Ophthalmic complications after spinal surgery. Spine 1997; 22: 1319-1324.

49 Roth S, Nunez R, Schreider BD. Unexplained visual loss after lumbar spinal fusion. J Neurosurg Anesthesiol 1997; 9: 346-348.

50 Alexandrakis G, Lam BL. Bilateral posterior ischemic optic neuropathy after spinal surgery. Am J Ophthalmol 1999; 127: 354-355.

51 Lee LA, Lam AM. Unilateral blindness after prone lumbar spine surgery. Anesthesiology 2001; 95: 793-795.
52 Milner GAW. A case of blindness after bilateral neck dissection. J Laryngol Otol 1960; 74: 880-885.

53 Kirkali P, Kansu T. A case of unilateral posterior ischemic optic neuropathy after radical neck dissection. Ann Ophthalmol 1990; 22: 297-298.

54 Pazos GA, Leonard DW, Blice J, Thompson DH. Blindness after bilateral neck dissection: case report and review. Am J Otolaryngol 1999; 20: 340-345.

55 Warner ME, Warner MA, Garrity JA, MacKenzie RA Warner DO. The frequency of perioperative vision loss. Anesth Analg 2001; 93: 1417-1421.

56 Dunker S, Hsu HY, Sebag J, Sadun AA. Perioperative risk factors for posterior ischemic optic neuropathy. J Am Coll Surg 2002; 194: 705-710.

57 Worrell L, Rowe M, Petti G. Amaurosis: a complication of bilateral radical neck dissection. Am J Otolaryngol 2002; 23: 56-59.

58 Wessels IF. Posterior ischemic optic neuropathy during general surgery. Am J Ophthalmol 1987; 104: 555-556.

59 Remigio D, Wertenbaker C. Post-operative bilateral vision loss. Surv Ophthalmol 2000; 44: 426-432.

60 Rizzo JF, Lessell S. Posterior ischemic optic neuropathy during general surgery. Am J Ophthalmol 1987; 103: 808-811.

61 Savino PJ, Burde RM, Mills RP. Visual loss following intranasal anesthetic injection. J Clin Neuroophthalmol 1990; 10: $140-144$.

62 Asensio JA, Forno W, Castillo GA, Gambaro E, Petrone P. Posterior ischemic optic neuropathy related to profound shock after penetrating thoracoabdominal trauma. South Med J 2002; 95: 1053-1057.

63 Luscavage LE, Volpe NJ, Liss R. Posterior ischemic optic neuropathy after uncomplicated cataract extraction. Am J Ophthalmol 2001; 132: 408-409.

64 Retout A, Charlin JF, Brasseur G, Didier T. Amaurose lors de la chirurgie du strabisme. A propos d'un cas. Bull Soc Ophtalmol Fr 1989; 89: 247-249.

65 Cheng MA, Todorov A, Tempelhoff R, McHugh T, Crowder $\mathrm{CM}$, Lauryssen $\mathrm{C}$. The effect of prone positioning on intraocular pressure in anesthetized patients. Anesthesiology 2001; 95: 1351-1355.

66 Hayreh SS. Anterior ischemic optic neuropathy-VIII. Clinical features and pathogenesis of post-hemorrhagic amaurosis. Ophthalmology 1987; 94: 1488-1502.

67 Duke-Elder S, Wybar KC. Systems of Ophthalmology, Vol 2. London: Kimpton, 1961, pp 643-645.

68 Hoyt WF, Luis O. Visual fiber anatomy in the infrageniculate pathway of the primate. Arch Ophthalmol 1962; 68: 94-106.

69 Hayreh SS, Podhajsky P. Visual field defects in anterior ischemic optic neuropathy. Doc Ophthalmol Proc Ser 1979; 19: 53-71.

70 Gerling J, Meyer JH, Kommerell G. Visual field defects in optic neuritis and anterior ischemic optic neuropathy: distinctive features. Graefes Arch Clin Exp Ophthalmol 1998; 236: 188-192.

71 Hayreh SS. In vivo choroidal circulation and its watershed zones. Eye 1990; 4: 273-289.

72 Hayreh SS. Posterior ciliary artery circulation in health and disease: The Weisenfeld Lecture. Invest Ophthalmol Vis Sci 2004; 45: 749-757. 